\title{
The Role of School Social Climate in Assessment of Home Economics Subjects at High Schools in Masvingo, Zimbabwe
}

\author{
Lilian Manwa \\ Great Zimbabwe University, Faculty Of Education, P.O. Box 1235, Masvingo, Zimbabwe \\ Email: lilianmanwa@gmail.com
}

Accepted: March 11, 2013 Published: April 30, 2013

Doi:10.5296/jsr.v4i1.3605 URL: http://dx.doi.org/10.5296/jsr.v4i1.3605

\begin{abstract}
This interpretive inquiry sought to find out the role of school social climate in assessment of home economics subjects at high schools in Masvingo, Zimbabwe. The inquiry employed a descriptive survey in order to unveil the factors that contribute to a school social climate and its effects on the teaching and assessment of Home Economics practical coursework. A descriptive survey was best for a relative large sample. In-depth interviews and open ended questionnaires were the instruments used to collect data. Collected data were presented in both descriptive and narrative forms. The sample was purposely selected from a population of thirty schools and the sample comprised of forty eight administrators, home economics The research findings indicated that the factors that contributed to the school social climate were the academic performance of students, home economics teacher-administration relationship, teacher-pupil, teacher-teacher and school-community relationships. The effects of the social climate were many and adverse and mostly linked to poor mark allocation due to bias and stress. The study is intended to benefit teachers, administrators, pupils and the community by enlightening them on the importance of good relations; as these contribute to the good school social climate. The study recommends that high levels of professionalism for teachers in assessment of practical skills can be attained during regular briefing, in service training courses and giving professional guidance on good public relations.
\end{abstract}

The school social environment has a strong positive relationship with teaching, learning, assessment of students' practical work, students' ratings of their overall school satisfaction, students' self-esteem, and academic performance (Tope, 2012:5; Adekola, 2012:282). The role of school social climate in assessment of Home Economics (H.E.) subjects has been receiving little attention by most researchers. Hence the need to study the role of school social climate in assessment of home economics subjects at high schools in Masvingo, 
Zimbabwe.

This is a follow up study of the role of school climate in quality assessment of home economics subjects by Lokadhia Manwa and Lilian Manwa which explored the school climate factors in general. Most researchers were focusing on the school climate linked to the provision of resources and the general welfare of students, however, the school social climate may be an inhibiting factor for effective teaching, learning and assessment.

A positive school social or emotional climate exists when all students, teachers, parents and the community in general feel comfortable, wanted, valued, accepted, and secure in an environment where they can interact with caring people they trust (Marshall, 2003:2). This implies that the social climate refers to that invisible atmosphere of how people relate and this is usually possible in a democratic environment. The social climate includes, norms, values, and expectations that support people and make them feel socially, emotionally and physically safe (Cohen, Mccbe, Michelli and Pickeral, 2009:180). Brand (2006:3) states that school climate have been conceived as a set of conditions that influence student outcomes, in part by establishing norms and expectations for behaviour. Brand (2006:3) also says that the definition of school social climate usually encompasses dimensions of the perceived social environment that: (a) have a contextual influence on the learning and development of students, and (b) remain stable over time.

The school climate in general is comprised of the following factors; respect, trust, high morale, opportunity for input, continuous academic and social growth, academic performance, cohesiveness, school renewal and caring (Marshall, 2003:2). School social climate specifically refers to spheres of school life such as safety, relationships in the teaching and learning environment (Cohen et. al., 2009:181). The social climate or ambience of the school and a good learning atmosphere is known to be a conducive environment for teaching, learning and assessment of coursework (Adekola, 2012:280). Clearly, school social climate is multi-dimensional and influences many individual, including students, parents, school personnel such as teachers and administration staff and the community (Marshall, 2003:2; Tope, 2012:5; Doctor, 2001:3). This study is therefore investigating the role of the school social climate on assessment of practical coursework of Home Economics subjects.

This study is concerned with the role of the school climate on quality assessment of H.E. practical subjects such as nutrition and fashion and fabrics at high school level. McMillan $(200: 1)$ states that fundamental assessment principles for teachers and school administrators are based on the fact that assessment is inherently a process of professional judgment. A professional judgement is not biased or subjective. Assessment in this regard has also an influence on the school social climate since it may be a source of conflicts (Tope, 2012:5).

Assessment decision-making is influenced by a series of tensions and anxieties (McMillan, 200:3). The decision making process requires an environment conducive for the difficult exercise. For the student, assessment determines the future not only of the student but also of the family. Sweeney (2012:13) suggests that assessment should contribute to learning 
beyond the immediate task, meet the needs of the present and prepare pupils to meet their own future needs, this is the double duty of assessment: assessment in the here-and-now which leaves students better equipped for the next task. Facts of this nature prompted this research since there are so many sensitive variables related to good assessment which includes the school social climate.

The focus is on practical continuous assessment in relation to the school social environment because, in Zimbabwe, thirty (30) to fifty (50) percent of the final mark which contributes to the final results for both ordinary and advanced levels is continuous assessment marks. Ordinary and Advanced level coursework articles contribute twenty (20) percent; practical examination contributes forty (40) percent while the theory examination is also forty (40) percent. These marks constitute the component of the final mark and are usually referred to as continuous assessment of coursework marks which make the assessment more tedious because the assessor has to be there physically (Nthiga \& Kagete, 2005:9). Such a scenario and breakdown of marks raises concerns of what will happen to the students if they fail to get a favourable environment for the assessment of their practical work which is more than fifty percent of the final mark.

The school social climate under this study consists of the academic performance of students, relationship between home economics teachers and the administration staff, teacher-pupil relationship, teacher-teacher relationship, parent-teacher relationship and the relationship of school community to local community. The social dialogue in this case should be given the precedence it deserves (Brand, 2006:7). All these social relationships have a great influence on the nature of school climate. The nature of the school social climate to a large extent determines the quality of teachers and then the quality of assessment (Adekola, 2012:280).

In this vein, the domain of climate is equated with just teacher support, personalisation, and sense of the school and local community, relationships, achievement emphasis, or school safety. While each of these may be important aspects of school climate, no single dimension encompasses the entire domain of school climate (Brand, 2006:7). This vein focused on the issues pertaining to relationships since they are the major contributors to the school social ambiance. Rather, numerous studies suggest that a comprehensive assessment of school climate should encompass multiple dimensions and these should include good relationships with all stakeholders (McMillan, 2000:3; Kuperminc, 2001:142; Brand, 2006:8). The teacher and administration relationship is pivotal in the support level the home economics teachers get from the school head and other administrators.

Zimbabwe is facing economic challenges which have led to poverty. Most schools are operating on very minimum resources and are struggling to fund practical subjects (Gaidzanwa, 2012:2; Watkins, 2000:40; Nziramasanga, 1999:172; Zvobgo, 1999:30; UNESCO, 2003:12). From the submissions of these educators, one can infer that whatever facilities are available, whatever content is taught, whichever environment the school is situated or the nature of the school social climate and whatever kind of pupils are given to 
teach, the important and vital role of the teacher cannot be overemphasised (UNESCO, 2003:13; Jantti \& Cox, 2011:1; Matoti, Junqueira \& Odora (2011:141). Given the situation that the home economics teachers have bad relationships with the administration, this may result in unfair distribution of resources.

School heads like any other being may negatively react to bad relations. Attitudes of headmasters towards the H.E. subjects may be negatively or positively enhanced by the type of relations. When the headmaster is pro Home Economics subjects, there may be a positive attitude and also some favours attached to the provision of resources. The scramble of resources requires an amicable solution which can only be reached when teachers and the administration are in good relations and have a mutual understanding (Hung, 2011:21; FAO, 2012:1; Zvobgo, 1999:30). It is necessary to establish the nature of the relationships that exist between administrators and home economics teachers in the district. The nature of relationships contributes to the school climate. Attitudes of home economics teachers towards the assessment of practical work can be influenced by the level of provision of resources and the general welfare at school. The school climate may create a barrier for good assessment procedures.

Matoti et al., (2011:141) argue that it is crucial to understand teachers' beliefs about their own effectiveness, known as teacher efficacy, as it helps to explain many instructional decisions that they make. Teachers to be effective, they need the social support from the administration. Teacher-administration relationship is also very critical in the teaching, learning and assessment of practical coursework (McMillan, 200:3). The relationships become more critical within the Home Economics department. Home economics teachers in Zimbabwe are in most cases women. It has been established by many researchers that women relationships are usually weak and temporary. This may reflect that home economics teachers are likely to face problems that are linked to their relationships.

All Home Economics teachers engage in assessment as part of their everyday work and applying assessment for learning principles involves working together and assisting one another in reaching good assessment decisions (Sweeney, 2012:1; Nthiga \& Kagete, 2005:9). Marking or assessment of practical coursework in Nutrition and Fashion and Fabrics usually requires the second opinion or moderation. The situation maybe very volatile when there are poor relationships in the Home Economics department and comments can be misinterpreted and this may results in quarrels and misunderstandings. Moderation of marks is very useful when done in a friendly environment where there are no links to a faulty finding mission (Ross, 2006:30; Doctor, 2001:3). Acceptance of changes done during moderation may also be done with respect and dignity and this may also result in a learning process of both teachers and pupils.

Teacher-pupil relationship has great influence on quality assessment of coursework items. Kim and Kim (2012:1) state that, in particular, teacher-student relationship was found to shape students' satisfaction with school life both at individual and school level. Teachers are in most 
cases biased towards good students and are negative to problematic pupils (Loukas, \& Murphy, 2007:295). Poor relationships influence the judgement of the teacher when assessing pupil's work. Continuous assessment is usually difficulty in a in a situation when the teacher-pupil relationships are poor. Coursework garments need to be thoroughly assessed from the beginning. It is a process which requires mutual understanding between the supervisor and supervisee since the process may be strenuous and very long (Pianta, La Pero, Payne, Cox, \& Bradley, 2002:230).

Several stages should be passed before reaching the final stage and the final stage also requires assessment. The road may be difficult if the relations are poor. A pervasive pattern of relationships has been found between climate dimensions and students' academic, behavioural, and socio emotional adjustment, even after partialling out the other effects on student outcomes (Brand, 2006:6 Pianta, et.al. 2002:230). Pupils may fail to take advice and corrections when they have negative feelings about their teachers. H.E. subjects are commonly done by female students which may also be problematic in that it will be females to females. Female to female relationships are usual a cause for concern (Tella, 2008:18).

There was a common understanding among students that practical subject teachers especially females are too strict and intolerant especially when they are stressed (Marshall, 2003:2). Such labels may cause pupils to have negative attitudes towards home economics teachers. Parent-teacher relationship influences the quality of assessment in that parents in Zimbabwe are the main sponsors of education of their children (Mavhunga, 2009:33; Gwarinda, 2001:41; Nziramasanga, 1999:172; The World Bank report, 1988:2). Practical subjects require a lot of support in terms of the supply of consumables and equipment by parents. It is impossible for assessment to take place, for examples, where there are no fabrics in Fashion and Fabrics or no food to cook in Nutrition. Thus, the availability of resource materials is essential in the teaching, learning and assessment of practical subjects.

Parents may have an influence on the choice of subjects and may encourage or discourage their children from doing H.E. Subjects. It is in this case that parent-teacher relationship may cause the H.E. subjects to be popular or unpopular. The equation is simple, no or very few subjects takers, very little of quality assessment takes place. Home economics teachers have a task of establishing relationships with parents in the local community through their children or through socialisation. Good morals by home economics teachers may also enhance relationships with the parents or the local community in general (Hee Chee, Pino \& Smith, 2005:2). It seems that to attain a good school social climate requires the effort of all stake holders. The school-local community relations are crucial in the teaching, learning and assessment of children's work.

The culture at the school is greatly influenced by the local community and also the school culture may influence the local community positively or negatively. A hostile community may cause the teachers to develop negative attitudes towards pupils from the local community. Assessment of work for practical subjects inevitable involves the local 
community. Displays of children's work attract comments from the community. The community may develop an interest in H.E subjects if the practical work is attractive and of good quality.

Continuous assessment of practical work is pivotal in producing good products. Pupils who do Nutrition as a subject may be known of being good cooks and then inspire the parents and the community which may result in them contributing more to the subjects. In the case where the school is part of the community and there are good relations, the community may have a burden of the needs of the school and work hard in order to give support to the school. Home economics teachers may also benefit from the good relationship of the school and the local community since they will be able to get support when advising their children. An early diagnosis of problem areas can help eradicate any stumbling block a pupil may have and can help the pupil understand what they need to do to improve (Sweeney, 2012:10).

Coursework garments and meals may be products of the joint venture of the teacher and pupil and the community in general, for instance, pupils may be encouraged to use locally available foods when planning meals and use methods of cooking which improve the taste of food. This may attract the support of the local leaders and the community in general. Sponsorship links may be obtained through the local civic leaders. Free intervention programs which are a brain child of the community may be very useful in achieving quality assessment.

For effective teaching and learning to take place there are many variables involved and one of the most important variables is a good social environment where all people are treated fairly and with dignity regardless of the social status of an individual (Tope, 2012:5). Poor social relationships at school lead to tension, suspicion and factionalism which may divide the community, and this may usually cause the school to faces challenges of attaining good academic results of pupils. The pass rate may be affected in a great way.

Good social relationships encourage good citizenship and a cooperative attitude. Internal fights within the school or within the department may be stressful. A stressed mind is known to be weak in good judgements. Good judgements are a product of a good mind. Continuous assessment of coursework requires a very sound mind free of stress. Strenuous relationships are usually too demanding, people involved will be busy trying to fight back or revenge. If it is parents-teacher or student-teacher relationship that is bad the coursework assessment exercise may be used as the ground to settle scores and this may result in biased assessment.

Distribution and sharing of school resources are done amicably when the social school climate is good. The administration leaders may be encouraged to use fair ways of distributing resources if all members are cooperative and loyal to the system (Gaidzanwa, 2012:1; Mavhunga, 2009:33; Gwarinda (2001:41). The following objectives were used to unveil the factors that influence the social school climate and how these affect quality assessment of coursework. 1) to establish the factors that contribute to a school social climate. 2) to find out the effects of the school social climate on the teaching and assessment of Home 
Economics practical coursework.

\section{Research Methods}

This qualitative inquiry employed a descriptive survey in order to capture the factors that influence the social climate of high schools in Masvingo district, Zimbabwe and their effects on the assessment of practical course work of Home Economics subjects. The study of human behaviour requires the qualitative paradigm because human behaviour is difficult to quantify (Cohen, Manion \& Morrison 2011). The quality of a research study is largely determined by the relationship between the topic, paradigm, research method and the instruments used to collect data. Hence, need to understand in detail the methodological procedure.

The qualitative paradigm involving a descriptive survey design was considered the best approach when investigating relationships. Lacour \& Tissington (2011) and Denzin \& Lincolin (2011:5) define qualitative as an emphasis on processes and meanings that are not rigorously examined or measured in terms of amounts that are difficult to quantify. Sidhu (2003:111) also propose that ethnographic studies which deal with human behaviour are best studied qualitatively since it is difficult to quantify human behaviour. The sample was purposely sampled from a population of thirty schools with an average of two hundred pupils comprised of six school heads; six school deputy heads, twelve home economics teachers and twenty four pupils who were taught by the selected teachers were also part of the sample.

A descriptive survey design examines a relatively large population and probes deeply and analyses interaction between factors (Best \& Kahn, 1993:93; Neuman, 2006:308). The descriptive design is best because the study of human behaviour requires a close examination of feelings, emotions and attitudes (Sidhu, 2003:110). Neuman (2000:122) and Bogdan \& Biklen (1992: 62) assert that data on cultures and human data is soft data. Qualitative data is soft data which is difficult to handle statistically (Neuman, 2000:122; Neuman, 2006:222). Sudhu (2003:111) states that a descriptive survey is a method which attempts to describe and interpret what exists at present in the form of conditions, practices, processes, trends, effects, attitudes and beliefs.

In-depth interviews or a conversation with a purpose were the major tool used to solicit data from the school administration leaders and the home economics teachers. Neuman (2000:272) and Boyce \& Neale (2006:2) define an in-depth interview as a conversation with a purpose which allows person to person discussion. Upadhya \& Singh (2010:36) suggest that the use of interviews is necessary when the issues involved are somehow sensitive. Most people have problems in separating work and personal relationships. The use of the interview was best in that participants were encouraged to tell the truth since face to face interviews demand some level of accountability unlike questionnaires which one may be careless with words.

The questionnaires were distributed to the twenty four pupils who were doing home economics; four pupils from each of the classes taught by the selected six home economics 
teachers were purposefully selected. Bhatt (2007:196) and Neuman (2006:308) state that open ended questionnaires are appropriate when collecting data from multiple sources. The open ended questions were used in order to give room for self expression. Pupils were given the questionnaires so that they had the freedom to say out their views without fear of victimisation. Cohen, Manion \& Morrison (2011:317) posit that a questionnaire is a useful instrument for collecting survey data. The open-ended questionnaires were used for their main advantage of being quick while collecting a substantial amount of data. The interviews questions on the questionnaires were designed to gather data on the nature of social school climate that existed in their schools.

\section{Discussion And Analysis}

The results on the factors that contribute to a social school climate indicated that the major factors such as the academic performance of students, home economics teacher-administration relationship, teacher-pupil, teacher-teacher and school-community relationships have a great influence on the school social climate and coursework assessment. These relationships were seen to be influencing the overall school culture which included norms and values. Pickeral, Evans, Hughes, \& Hutchison (2009:2) assert that one of the fundamentally important dimensions of school social climate is relational, i.e., how connected people feel to one another in school, and the nature of the school-family-community partnerships.

Ethics and codes of contacts are in most cases based on relationships (Pickeral et. al., 2009:1). Most headmasters, deputy heads and senior staff submitted that well behaved teachers were treated with respect and where good relationships prevail preferences were given to such teachers. Tope (2012:5) supports the fact that good relationships and treating one another with respect contribute to good school social climate. One senior participant said that 'Mukuru wedu ndinomunyara nokuti munhu akanaka' meaning that we treat our school head with great respect because he has good public relations. Most home economics teachers revealed that effective teaching and assessment of practical work can be almost impossible if the school social climate is unbearable.

One home economics teacher who was dealing with a school head with poor public relations lamented the ordeal. Sour relationships between administration and the H.E. department contribute greatly to the school social climate. Good morals are usually a product of good relationships which are open for correction. Pickeral et. al. (2009:8) state that high quality citizenship: civic purpose of education; collaboration and cooperation (mutual trust and positive interactions, student input in planning/problem-solving); and, engagement in the community (open dialogue, respectful communication). Some home economics teacher brought in the idea of norms and values as the major factors that influence the social school climate. One participant pointed out that if the culture of the school lacks good values and norms the relationships among members are likely to be weak and problematic. In the case of H.E subjects, if the school head does not value the subjects may also look down upon the 
teachers. This may lead to home economics teachers to have inferiority complex that may result in poor judgement where as confidence may also lead to sound judgement.

Most school heads and home economics teachers revealed that the economic status of the school have a greater influence on the social school climate. It is known through research that poor families, communities and even countries are less stable in relations (Ebhohimen, 2006:4). Most fights among people and nations or poor relations which are due to the scramble for resources (Mavhunga, 2009:33; Gwarinda, 2001:41). People fight when they lack basic needs and wants. This implies that poverty can be a susceptible source of poor relationships. Lack is stressful echoed another home economics teacher who said that people relate well if their needs are satisfied. Assessment of practical coursework is greatly influenced by the soundness of the physical and mental conditions (UNESCO, 2003:10). The school social climate has great influence on the teacher's psychological, emotional, social and economic state, all of which influence quality of assessment (Watkins, 2000:39).

Relationships between the teaching staff was rated the other factor that influenced the social school climate. A school social atmosphere characterised by strife, envy, malice and jealousy is regarded to as a poor school social environment (Adekola, 2012:282). Teachers who have bad relationships usually find themselves in hot arguments and debates which are fruitless. Instead of encouraging are another, the scenario may be of discouragement. Appreciating one another and working as a team was also a good factor that contributes to a good school social climate.

The school-community relationship was also considered as a factor that influenced the school social climate. In Zimbabwe, some schools are considered to be under the authority of the traditional leaders for example the Shangani tribe consider their local school as "Chikoro chahina" meaning to say that the school belongs to us the community. This implies that from the school head to all the teachers they belong to the community. This maybe a big advantage in docile communities but can also be a disadvantage in hostile communities. One respondent said that the community may feel jealous if their children are jobless or are failing to secure passes which are required of them to teach, such issues were a cause for concern at one school were the headmaster is one of the local community leaders and manages the school from within and from outside. Teachers from far places are termed 'Mabvakure' meaning to say that teachers who are from very far places and are also strangers. The demands from such communities may be costly, for example, payment of tributes to local leaders. Such demands may cause poor relationships.

The results revealed that the effects of the school social climate on teaching, learning and assessment of practical coursework were established to be many and adverse. The effects were mostly linked to poor mark allocation due to bias and stress. The effects of economic factors were seen to be major and cause for concern from the six schools. From the six schools involved in the study, five lamented the effects of economic hardship on the teaching, learning and assessment. One school head said that lack of resources makes people to be 
unnecessarily very sensitive, minor issues may cause tension to rise and lead to conflicts (Gaidzanwa, 2012:2; and UNESCO, 2003:12).

Effective teaching, learning and assessment effectively take place where all the basic needs are met (Kapungu, 2007:2). One of home economics teachers said that it is not difficulty to maintain good relations when all minimum requirements for practical lessons are met. Stress is visible in such a situation and this may cause strained relationships. Stressed teachers may concentrate with issues that reduce stress and forget the co-business of teaching and assessing pupil's work (Pickeral et. al., 2009:10). Thorough supervision of practical coursework is pivotal in achieving good results. Pupils require feedback on time so that they correct their mistakes before final submission. Most home economics teachers expressed that they fail to meet their deadlines and targets due to social life problems including strained relationships with administration.

Senior teachers and experienced home economics teachers displayed their maturity in what they considered important as far as their profession is concerned. One senior home economics teacher said that it is very important to relate to others well and try to build and maintain relationships (Marshall, 2003:1). One junior home economics teacher said that the old folk are difficult to work with, their demands are too much. It seemed that most young teachers were blaming others for all their problems. They did not want to be accountable. Two headmasters with masters' degrees and mature stated that it is the duty of the school head and his or her deputy to build relationships and maintain them at all levels.

Maturity and level of education seemed to have contributed a lot in enhancing social relationships (Pickeral et. al., 2009:8). Among the six heads of school there was one female school head that seemed to be building relationships with all stake holders. She said that the social environment of the school is critical in teaching and assessing children's work. Most school heads agreed in principle that a hostile environment is not conducive for effective teaching, learning and assessment. Good assessment and evaluation is possible when the assessor is free of stress and has a sound mind.

The performance of pupils is likely to improve when the teachers operate in a friendly environment (Pianta, et.al. 2002:230). One home economics graduate teacher said that a frustrated teacher may relieve his or her stress on pupils. Frustrated pupils can also develop negative tendencies which may cause the teachers to retaliate and mistreat them. Consolvo, Smith, Matthews, LaMarca, Tabert and Powledge (2005:3) complement the results that relationships influence results since people tend to react when under pressure. It has been noted that most pupils said that teachers who are motivated to work and are happy to teach assess the work of the students objectively. Some pupils submitted that female teachers were the most affected by stress and usually express their dissatisfaction openly. They are likely to burst in front of pupils when they experience sour relationships.

There was a general feeling among the pupils that they find it difficult to operate effectively 
when the teachers are not friendly and are not happy. Fairness in assessment can only be achieved when the school social ambiance is conducive for good relationships. People who relate well treat each other fairly said one of the teachers. Assessment of practical work requires an objective mind in order to allocate marks which one deserves (Cohen et. al., 2009:182). Some pupils said that in some cases a better article or dish may be allocated less marks as compared to poor dishes or garments.

Ross (2006:6) state that involving students in the assessment of their work, especially giving them opportunities to contribute to the criteria on which that work will be judged, increases student engagement in assessment tasks. Teachers may be biased towards students whom they relate well with. One home economics teacher said that it is easier to deal with pupils who are friendly and obedient. She further said that as a human being you may favour students who are disciplined and who have a good relationship with other pupils.

Good relationships with the community were seen to be beneficial to the school. Parents or the community in general can help to build a good school social climate. SAMHSA (2011:1) suggest that education is increasingly viewed as shared responsibility of educators and families. Parental involvement continues to be important even as children mature. They can provide material and financial support which reduce human suffering and boost the morale of the teachers. It is easy to relate well when people are happy and stress free. Financial incentives from the community and NGOs can motivate teachers to work hard and assess the children's work objectively (Watkins, 2000:39; Nziramasanga, 1999:172).

The community can also assist in discipline. Chrzanowski and Thompson (1999:13) suggest that the collaboration between several people within schools, churches and the civic leaders is an example of a connected community. A connected community is intact and norms and values are considered important. Pupils apply themselves more affectively when they are disciplined. Good social relations induce productive cooperation (Spagnolo, 2009:4). Most home economics teachers said that practical subjects require extra patience and this can be achieved by pupils who are self disciplined. Parents and the community are the major socialising agents and can assist in producing committed pupils. Agabrian (2007:28) state that almost all the families care about their children, wish for them to have success and they try to obtain as much information as they can from the school and the community, therefore they are good partners in their children's education. The school and community good relations can also be used as a platform to motive pupils to do well (Brand, 2006:7). Achievement awards from the community are treated with respect by most pupils and teachers. Such awards can motivate both teachers and pupils to work harder.

\section{Summary And Conclusion}




\section{$\Lambda$ Macrothink}

The focus of the study was on the role of the social climate of high schools in assessment of coursework in Home Economics subjects. The major factors that were established to be contributing to the social climate were home economics teacher-administration relationship, teacher-teacher relationship, teacher-pupil, teacher-parent and the school community and the local community relationship. The culture of the school was seen to be greatly influenced by the social relationships of all the stake holders involved. A good school social climate was defined as the environment that involved all stake holders fairly and where staff, parents and pupils relate well. The effects of a poor school social climate were seen to be quite difficult to operate in and at the same time produce good results.

Assessment of coursework garments requires to be done by someone with a stable mind and is objective. Life pressures were seen to influence the objectivity and cause one to be biased. A good school social climate was termed the correct environment for effective teaching, learning and assessment of pupils' work. Continuous assessment is a very important component of the final results since there is to be done in a free and fair environment. Marks which contribute to the final assessment should be marked in a friendly environment to ensure that marks allocated to the products really match the quality of the product.

Teachers who moderate practical coursework marks in a good social environment reduce the effects of favouritism. Internal moderation can be effective if it is done objectively and without the fault finding attitude. Collaborative effort when trying to achieve good results can be done by teachers who work together. Mistrust and suspicion is the root cause of individualism which discourages teachers to compliment one another's strengths and weaknesses.

This study recommends that school social climate be treated with the importance it deserves. Most people do not value their relationships hence need to educate school heads, teachers, pupils and parents on the importance of the school climate. Guidance and counselling lessons should emphasise the importance of good relationships. Workshops for teachers should include teachings of good working relationships. School heads are also encouraged to exercise fairness in all matters. Discipline should be the culture of the school and that should be for both pupils and staff members.

Provision of recourses should be done and fairly distributed inorder to maintain good relations and create an environment free of stress. Critical areas such ordinary level coursework garments should be given the priority when doing procurement since the coursework garments are examinations material. The government and Non Governmental Organizations should increase their funding of practical subjects in order to improve the provision of resources so as to achieve quality assessment. Assessing coursework garments which were done hurriedly can be a difficult task. Quality garments leads to quality assessment and good marks. More studies on school social climate are necessary to get the real solution and also to find ways of improving the school social climate. 


\section{Macrothink}

This study also recommends that high levels of professionalism for teachers in assessment of practical skills can be attained during regular briefing, in service training courses and giving them professional guidance on good public relations. Simple courses can be organized at district levels to give teachers basic assessment skills and basic public relations. Assessment of practical skill subjects forms an important and integral part of the National Examinations hence the need to improve the assessment process through creating a good school social climate.

\section{References}

Adekola, B. O. (2012). Home and Social Factors as Determinants of Students'Achievement in Senior Secondary Schools English Comprehension for South Western States. (Master's Thesis; Downloaded March, 2012).

Agabrian, M. (2006). Relationships Between School and Family: The Adolescents' Perspective [83 paragraphs]. Forum Qualitative Sozialforschung / Forum: Qualitative Social Research, 8(1), Art. 20, http://nbn-resolving.de/urn:nbn:de:0114-fqs0701208

Bhatt, P. (2007). Educational Psychology. India: Author Press.

Best, J.W. \& Kahn, J.V. (1993). Research in Education. $7^{\text {th }}$ edition. Boston: Allyn and Bacon. Bogdan, R.C. \& Biklen, S.K. (1992). Qualitative Research in Education. An Introduction to Theory and Methods. $2^{\text {nd }}$ edition. Boston: Allyn and Bacon.

Brand, S. (2006) Assessment of Classroom and School Climate. Significance of School Climate for Students' Learning and Development. http://www.education.com/referennce/article/schoolclimate

Chrzanowski, D., Rans, S. \& Thompson, R. (2009). Building Mutually Beneficial Relationships Between School and Communities. The Role of a Connector. A Publication from the Assert Based Community Development Institute at North Western University.

Cohen, L., Manion, L \& Morrison, K. (2011). Research Methods in Education. $7^{\text {th }}$ edition. London: Rutledge.

Consolvo, S., Smith, I. E., Matthews, T. LaMarca, A.,Tabert, J. and Powledge, P. (2005). Location Disclosure to Social Relations. Why, When and What People Want to Share. Intel Research Seattle. 4 (2) 7 81-90

Crawford, C. M., Carlsen, R., McFerrin, K., Price, J., Weber, R \& Willis

D. A. (2006). The Impact of Assessing Technology Competencies of Incoming Teacher Education Students.

Denzin, N. K. \& Lincolin, Y. S. (2011) Handbook of Qualitative Research. $4^{\text {th }}$ edition. Los Angeles: Sage Publications.

Boyce, C. \& Neale, P. (2006) Conducting In-depth Interviews: A Guide for Designing and Conducting In-depth Interviews for Evaluation Input. USA: Pathfinder International. information@pathfind.org.

Gaidzwanwa, R. (2012). Activism, Feminist Chronicles, Gender, Women, Zimbabwe. Feminist 'Chronicles' Month/word.com (Downloaded October, 2012). 


\section{$\Lambda$ Macrothink}

Journal of Sociological Research

ISSN 1948-5468

2013, Vol. 4, No. 1

Hee Chee, K., Pino N.W. \& W.L. Smith, W.L. (2005). Gender Differences in the Academic, Ethic Achievement. College Student Journal. Volume. 2: 1-12. September 2005.

Kapungu, R. S. (2007). The Pursuit of Higher Education in Zimbabwe: A Futile Effort? A Paper Prepared for the Centre for International Private Interprise (CIPE) 2007 International Essay Competition on 'Educational Reform and Employment Opportunities'.

Kim, D. H. and Kim, J. H. (2012). Social Relations and School Life Satisfaction in South Korea.

http://link.springer.com/accesspage/article/10.1007/s11205-012-0042-8? coveraImageUrl=/sta tic-content/0.6144/covers/journals/879/11.205.jpg

Kuperminc, G. P., Leadbeater, B. J., \& Blatt, S. J. (2001). School social climate and individual differences in vulnerability to psychopathology among middle school students. Journal of School Psychology, 39, 141-159.

Lacour, M. \& Tissington, L. D. (2011). Educational Research and Reviews. Academic Journals, July 2011 . Volume. 6. (7): 522-527.

Loukas, A., \& Murphy, J. L. (2007). Middle school student perceptions of school climate: Examining protective functions on subsequent adjustment problems. Journal of School Psychology, 45, 293-309.

Matoti, S.N., Junqueira, K.E., \& Odora, R.J. (2001). A comparative study of pre-service teachers' self-efficacy beliefs before and after work-integrated learning. SAJHE 25 (6), 1140-1177.

McMillan, James H. (2000). Fundamental assessment principles for teachers and school administrators. Practical Assessment, Research \& Evaluation, 7(8). http://PAREonline.net/getvn.asp?v=7\&n=8 . A peer-reviewed electronic journal. ISSN 1531-7714 1-9.

Mitrofanova, Y. Building Community-Schools: Relations School \& Community Relationships. NEBLINE Newsletter e-mail: ymitrofanova2@unl.edu

Neuman, W. L. (2006). Qualitative and Quantitative Approaches. $4^{\text {th }}$ edition. Boston: Allyn and Bacon.

Nthiga. J. \& Kagete P. M. (2005). Enhancing the Quality of Education Through Assessment: Assessing Practical Skills Subjects; the Kenyan Experience. Kenya National Examinations Council. 1-17.

Nziramasanga Commission of Inquiry. (1999). Report of the Presidential Commission of Inquiry into Education and Training (In Zimbabwe). Harare: Government Printers.

Pianta, R., La Pero, K. M., Payne, C., Cox, M. J., \& Bradley, R. (2002). The relationship of kindergarten classroom environment to teacher, family, and school characteristics and child outcomes. Elementary School Journal, 102, 225-238.

Pickeral, T., Evans, L., Hughes, W. \& Hutchison, D. (2009). School Climate Guide for District Policymakers and Educational Leaders.New York, NY: Center for Social and Emotional Education (www.schoolclimate.org).

Ross, J. A. (2006) Practical Assessment Research and Evaluation. The Reliability, Validity, and Utility of Self-Assessment Volume 11 Number 10, ISSN 1531-7714 1-72. 
SAMHSA. (2011). School-family Partnership Strategies to Children's Social Emotional and Academic Growth. www2ed,gov/parents/academic/help/hyc,html.

Sandhya, N. (2004). Research in Value Education. New Delhi: APH. Publishing Corporation.

Sidhu, K.S. (2003). Methodology of Research in Education. New Delhi: Sterling Publishers Pvt. Ltd.

Spagnolo, G. (1999). Social Relation and Cooperation in Organizations. Journal of Economic Behaviour and Organization. Vol 38. 1-25.

Sweeney, K. (2012) Home Economics Practical coursework; Generating more effective Learning using Assessment for Learning principles. info@ccea.org.uk.

Tope, O. (2012). Effects of Teachers' Competence on Academic Performance: A Case Study of Ikeja Local Government Area of Lagos State. Ego Books, Ogun State, Nigeria. EgoBooks.wwwometere.tk.

UNESCO. (2003). Gender and Education for All. The Leap to Equity. France UNESCO Publishing. United Nations Educational.

Upadhya, B. \& Singh, Y. K. (2010). Advanced Educational Psychology. New Dehli: APH. Publishing Corporation.

Vannatta, R., Ross, C. \& Banister, S. (2006). The Impact of Assessing Technology Competencies of Incoming Teacher Education Students. In C. Crawford et al. (Eds.), Proceedings of Society for Information Technology \& Teacher Education International Conference 2006 (pp. 189-191). Chesapeake, VA: AACE.

Retrieved from http://www.editlib.org/p/22029.

Watkins, K. (2000). The Oxfam Education Report. London: An Oxfam Publication.

Zvobgo, R. J. (1999). The Post-Colonial State and Educational Reform (Zimbabwe, Zambia and Botswana). Harare: Zimbabwe Publishing House. 